\title{
ORIGINAL ARTICLE Evaluation of the effects of specific opioid receptor agonists in a rodent model of spinal cord injury
}

\author{
M Aceves, BB Mathai and MA Hook
}

Objective: The current study aimed to evaluate the contribution(s) of specific opioid receptor systems to the analgesic and detrimental effects of morphine, observed after spinal cord injury in prior studies.

Study design: We used specific opioid receptor agonists to assess the effects of $\mu$ - (DAMGO), $\delta$ - (DPDPE) and $\kappa-$ (GR89696) opioid receptor activation on locomotor (Basso, Beattie and Bresnahan scale, tapered beam and ladder tests) and sensory (girdle, tactile and tail-flick tests) recovery in a rodent contusion model (T12). We also tested the contribution of non-classic opioid binding using [+]- morphine.

Methods: First, a dose-response curve for analgesic efficacy was generated for each opioid agonist. Baseline locomotor and sensory reactivity was assessed $24 \mathrm{~h}$ after injury. Subjects were then treated with an intrathecal dose of a specific agonist and re-tested after 30 min. To evaluate the effects on recovery, subjects were treated with a single dose of an agonist and both locomotor and sensory function were monitored for 21 days.

Results: All agonists for the classic opioid receptors, but not the [+]- morphine enantiomer, produced antinociception at a concentration equivalent to a dose of morphine previously shown to produce strong analgesic effects (0.32 $\mu$ mol). DAMGO and [+]- morphine did not affect long-term recovery. GR89696, however, significantly undermined the recovery of locomotor function at all doses tested.

Conclusions: On the basis of these data, we hypothesize that the analgesic efficacy of morphine is primarily mediated by binding to the classic $\mu$-opioid receptor. Conversely, the adverse effects of morphine may be linked to activation of the $\kappa$-opioid receptor. Ultimately, elucidating the molecular mechanisms underlying the effects of morphine is imperative to develop safe and effective pharmacological interventions in a clinical setting.

Setting: USA.

Sponsorship: Grant DA31197 to MA Hook and the NIDA Drug Supply Program.

Spinal Cord (2016) 54, 767-777; doi:10.1038/sc.2016.28; published online 1 March 2016

\section{INTRODUCTION}

According to the Consortium for Spinal Cord Medicine, in the critical first few days following spinal cord injury (SCI), many patients will experience distressing pain and sensitivity that arises from trauma to the cord, the spinal nerves, the spinal fracture or from concomitant injuries. ${ }^{1}$ This pain will typically be treated with opioids and NSAIDs. Indeed, Neighbor et al. ${ }^{2}$ reported that $48 \%$ of 540 patients treated by a trauma team received opioid analgesia within $3 \mathrm{~h}$ of arrival to the emergency department. Although this study focused on the undertreatment of pain in the emergency setting, studies in our laboratory suggest that the effects of analgesics may be altered in the pathophysiological context of an injury. Specifically, our studies suggest that opioid use is contraindicated in the early phase of SCI. ${ }^{3-7}$ Acute morphine treatment increases tissue loss at the injury site, increases mortality, undermines weight gain, reduces recovery of motor and sensory function, and increases pain reactivity, even weeks after treatment. ${ }^{3-7}$ On the basis of these data, it would be tempting to suggest that morphine be eliminated as an analgesic after SCI. However, as pain is one of the most debilitating consequences of
SCI, we cannot afford to simply remove any potential analgesic therapy. Rather, it is imperative that we further our understanding of the molecular mechanisms underlying the effects of morphine and develop pharmacological interventions that can be used to improve the safety and efficacy of opioids.

To address this, the current experiments evaluated the consequences of selective opioid receptor activation in the SCI model. Morphine is primarily a $\mu(\mathrm{mu})$-opioid receptor (MOR) agonist, but it also interacts with the $\kappa$ (kappa)-opioid receptor (KOR) and $\delta$ (delta)opioid receptor (DOR) and with toll-like receptors in a non-classic manner. ${ }^{8,9}$ This suggests that morphine may exert adverse effects through any of these receptor systems. For example, whereas activation of the MOR is typically associated with analgesia, binding of morphine to the MOR is also thought to initiate G-protein-mediated protein kinase $\mathrm{C}$ translocation and activation, promoting the removal of the NMDA receptor $\mathrm{Mg}^{+}$plug ${ }^{10}$ and allowing $\mathrm{Ca}^{2+}$ influx. Chronic morphine exposure is also associated with the downregulation of glutamate transporters, directly contributing to the heightened activity of NMDA receptors. ${ }^{11,12}$ In this way, morphine may act through the 
MOR to potentiate NMDA receptor activation, maintaining central sensitization and hyperalgesia in the neural system and leading to excitotoxic cell death. ${ }^{13,14}$ Morphine may also undermine recovery of function after SCI by activating the KOR system. Behaviorally, Faden and colleagues ${ }^{15,16}$ have demonstrated that intrathecal administration of dynorphin (an endogenous KOR ligand) causes hindlimb paralysis in neurologically intact rats, and blocking the KOR improves neurological outcomes after a contusion SCI.

Alternatively, morphine may exert its negative effects through activation of non-classic opioid receptors found on immunecompetent cells. ${ }^{17-20}$ For example, research suggests that opioid ligands can bind to toll-like receptor 4 (the receptor that recognizes lipopolysaccharide) and its accessory molecules in a nonstereoselective manner, leading to glial activation and initiating the inflammatory response., ${ }^{91-23}$ The subsequent release of proinflammatory cytokines in the spinal cord has been shown to oppose opioid analgesia and facilitate pain. ${ }^{24,25}$ Importantly, in our SCI model, we have shown that morphine administration results in increased pro-inflammatory cytokine expression at the injury site and that blocking the interleukin-1 (IL-1) receptor during treatment with this analgesic prevents the morphine-induced attenuation of locomotor recovery. ${ }^{4}$ These data suggest that, by binding to nonclassic opioid receptors, morphine may alter the normal immune response following SCI, resulting in the adverse long-term consequences typically observed in this model.

On the basis of these hypotheses, and to more clearly dissociate the beneficial (analgesic) and deleterious consequences of morphine treatment, the experiments presented here examined the effects of classic and non-classic opioid receptor activation through the use of selective opioid agonists. Experiment 1 compared the analgesic efficacy of the classic ( $\mu$ (DAMGO), $\delta$ (DPDPE), $\kappa-2$ (GR89696)) and the non-classic ([+]- morphine) opioid agonists. All agonists for the classic opioid receptors produced analgesia at a concentration equivalent to an effective dose of morphine $(0.32 \mu \mathrm{mol})$ but, not surprisingly, the unnatural [+]- enantiomer of morphine did not produce analgesia. Experiment 2 assessed the long-term effects of the opioid agonists on the recovery of locomotor function. Whereas DAMGO and [+]- morphine did not affect long-term recovery, GR89696 significantly undermined locomotor function. The selective KOR agonist also increased the lesion size caudal to the injury site. Activation of the KOR system is sufficient to undermine locomotor recovery after SCI.

\section{MATERIALS AND METHODS}

\section{Subjects}

The subjects were male Sprague-Dawley rats obtained from Harlan (Houston, TX, USA). They were approximately 90-110 days old (300-350 g) and were individually housed in Plexiglas bins (45.7 (length) $\times 23.5$ (width) $\times 20.3$ (height) $\mathrm{cm}$ ) with food and water continuously available. Food consumption and subject weights were recorded daily. Following surgery, subjects were manually expressed in the morning (8:00-9:30 a.m.) and in the evening (6:00-7:30 p.m.), until they regained full bladder control (which was operationally defined as three consecutive days with an empty bladder at the time of expression), and were checked daily for signs of autophagia and spastic hypertonia. Subjects were classified as having spastic hypertonia if they showed abnormal increases in muscle tone accompanied by exaggerated tendon jerks. The rats were maintained on a $12 \mathrm{~h}$ light/dark cycle, and all behavioral testing was conducted during the light cycle. All of the experiments reported here were reviewed and approved by the Institutional Animal Care Committee at Texas A\&M University, and all NIH guidelines for the care and use of animal subjects were followed.

\section{Experimental design}

In Experiment 1 (A-D), dose-response curves were generated, recording sensory reactivity to nociceptive stimuli after treatment with the selective opioid receptor agonists. In total, 48 subjects ( $n=4$ for each agonist dose) were used for this experiment. Experiment 2 (A-C) assessed the effects of opioid receptor activation on long-term recovery of function. In total, 72 subjects ( $n=8$ for each agonist dose) were used for this experiment.

\section{Surgery}

Subjects received a moderate contusion injury using the Infinite Horizon spinal cord impactor (PSI, Fairfax Station, VA, USA). Briefly, subjects were anesthetized with isoflurane (5\%, gas), and, after a stable level of anesthesia was reached, the concentration of isoflurane was lowered to $2-3 \%$. The subject's back was shaved and disinfected with iodine, and a 5.0-cm incision was made over the spinal cord. Two incisions were made on the vertebral column on each side of the dorsal spinous processes, extending about $2 \mathrm{~cm}$ rostral and caudal to the T12-T13 segment. Muscle and connective tissue were then dissected to expose the underlying vertebral segments. Musculature around the transverse processes was cleared to allow for clamping of the vertebral spinal column. Next, the dorsal spinous processes at T12-T13 were removed (laminectomy), and the spinal tissue exposed. The dura remained intact. The vertebral column was fixed within the IH device using two pairs of Adson forceps. A moderate injury was produced using an impact force of 150 kdynes and a $1 \mathrm{~s}$ dwell time. After injury, a 15-cm-long polyethylene (PE-10) cannula, fitted with a stainless steel guiding wire (P01008, Ernie Ball Inc., Coachella, CA, USA), was threaded $2 \mathrm{~cm}$ under the vertebrae immediately caudal to the injury site. The tubing was inserted into the subarachnoid space. To prevent cannula movement, the exposed end of the tubing was secured to the vertebrae rostral to the injury using tissue adhesive (3M Vetbond Tissue Adhesive, 3M Animal Care Products, St Paul, MN, USA). The wire was then pulled from the tubing and the wound was closed using Michel clips. To help prevent infection, subjects were treated with 100000 units per kg Pfizerpen (penicillin $\mathrm{G}$ potassium) immediately after surgery and again 2 days later. For the first $24 \mathrm{~h}$ after surgery, rats were placed in a recovery room maintained at $26.6^{\circ} \mathrm{C}$. To compensate for fluid loss, subjects were given $3 \mathrm{ml}$ of saline after surgery. Michel clips were removed 14 days after surgery.

\section{Drug preparation}

DAMGO (MOR), DPDPE (DOR) and GR89696 (KOR) were obtained from Sigma-Aldrich (St. Louis, MO, USA). The unnatural [+]- enantiomer of morphine (National Institute of Drug Abuse, Bethesda, MD, USA) was also tested. DAMGO and DPDPE were dissolved in $10 \mu \mathrm{l}$ of distilled water. GR89696 was dissolved in $10 \mu \mathrm{l}$ of 34\% DMSO solution. [+]- morphine was dissolved in $10 \mathrm{~N}$ hydrochloric acid and then titrated with $1 \mathrm{~N}$ sodium hydroxide to $\mathrm{pH} 5-6$, which was diluted to the intended concentration with $0.9 \%$ saline $(16 \mu \mathrm{l})$ for injection. In all cases, the drugs were administered intrathecally, followed by a $10 \mu$ injection of saline to flush the catheter. Drug administration took place $24 \mathrm{~h}$ following surgery.

\section{Assessments of sensory reactivity}

Thermal reactivity was assessed immediately before, and $30 \mathrm{~min}$ after, drug administration using radiant heat in the tail-flick test. Subjects were placed in restraining tubes and allowed to acclimate to the tail-flick apparatus (IITC Life Science Inc., Woodland Hills, CA, USA) and testing room (maintained at $26.5^{\circ}$ C) for $15 \mathrm{~min}$. Prior to testing, the temperature of the light, focused on the tail, was set to elicit a baseline tail-flick response in approximately $4 \mathrm{~s}$ in an intact rat. This pre-set temperature was then maintained across the SCI subjects. In testing, the latency to flick the tail away from the radiant heat source (light) was recorded. If a subject failed to respond, the test trial was automatically terminated after $8 \mathrm{~s}$ of heat exposure. Two tests occurred at 2-min intervals, and the last tail-flick latency was recorded.

To test mechanical reactivity, von Frey filaments (Semmes-Weinstein Anesthesiometer, Stoelting Co., Chicago, IL, USA) of increasing strength were applied every $2 \mathrm{~s}$ in sequence to the plantar surface of the paw. The stimuli were presented until subjects exhibited a motor (paw withdrawal) and vocalization response. The intensity of the stimuli that produced the responses was reported 
using the formula provided by Semmes-Weinstein: Intensity $=\log 10(10000 * \mathrm{~g}$ force). If one or both responses (motor and vocal) were not observed, testing was terminated at a force of $300 \mathrm{~g}$. Each subject was tested twice on each foot in a counterbalanced ABBA order.

Tactile reactivity was also assessed at the level of injury using the girdle test. ${ }^{26}$ For this test, the girdle region was shaved, and a grid map of the girdle zone for allodynic responding was made on the rats using an indelible marker (44 squares). To ensure that the rats remained calm for testing, they were handled for $5 \mathrm{~min}$ immediately prior to beginning the girdle test. A von Frey filament with bending force of $204.14 \mathrm{mN}$ ( $26 \mathrm{~g}$ force) was then applied to each point on the grid, and vocalization responses were recorded and mapped onto a grid map of that animal. As animals do not normally vocalize to this stimulus, a vocalization response indicated that a noxious stimulus was experienced. In mapping the area of response, the number of vocalizations is recorded $(\mathrm{Nv})$ and normalized by the following formula: $(\mathrm{Nv} \times 100) /$ total number of applications (44), indicating the percent vocalizations out of the total number of applications. To evaluate the long-term recovery of sensory function in Experiment 2, reactivity thresholds were re-assessed after day 21 post injury, as described above.

\section{Locomotor recovery}

Locomotor behavior was assessed for 21 days post injury, using the Basso, Beattie and Bresnahan (BBB) scale ${ }^{27}$ in an open enclosure (a blue children's wading pool, $99 \mathrm{~cm}$ in diameter, $23 \mathrm{~cm}$ deep). Baseline motor function was assessed on the day following injury and prior to drug treatment. Locomotor behavior was then scored once per day for 1 week (days 2-7). Subjects were scored every other day from day 9 to day 15 and every third day on days 18 and 21. Because rodents often remain motionless (freeze) when first introduced to a new apparatus, subjects were acclimated to the observation fields for $5 \mathrm{~min}$ per day for 3 days prior to surgery. Each subject was placed in the open field and observed for $4 \mathrm{~min}$. Care was taken to ensure that all investigators' scoring behavior had high intra- and inter-observer reliability (scores were subjected to a Pearson correlation, with a minimum coefficient of 0.89 ) and that they were blind to the subject's experimental treatment.

Locomotor scores were transformed, as described by Ferguson et al., ${ }^{28}$ to help assure that the data were amendable to parametric analyses. Briefly, this transformation pools BBB scores of $2-4$, removing a discontinuity in the scale. The transformation also pools scores from a region of the scale (scores of 14-21) that is very seldom used under the present injury parameters. By pooling these scores, we obtain an ordered scale that is relatively continuous with units that have approximately equivalent interval spacing. Meeting these criteria allows us to apply metric operations (computation of mean performance across legs), improves the justification for parametric statistical analyses and increases statistical power.

Additional measures of motor recovery were obtained at the end of the 21-day recovery period using ladder walk ${ }^{29}$ and beam walk ${ }^{30-32}$ tasks. Prior to testing, subjects were habituated to the experimental context for 3 days ( 8 min per day). During this period of familiarization, they were trained to traverse a wide beam $(48.3 \mathrm{~cm})$ to enter a black box positioned at the end of the beam runway. The beginning of the runway is brightly lit, motivating subjects to move toward the dark box. They were left in the box for $2 \mathrm{~min}$ after they had traversed the beam. Subjects were then tested on the beam and the ladder walk test.

The beam walk test provides a comparative index of the postural stability of the subjects, as well as a gross measure of paw placement abilities. In this test, the subject's ability to traverse a tapered beam was assessed. The beam was 6.75 in $(17.14 \mathrm{~cm})$ wide at the start and 0.375 in $(0.95 \mathrm{~cm})$ wide at the other end. We recorded the width at which each foot failed to plantar place on the beam. The average width across the two legs was used as an index of beam walk performance.

The ladder task provides a measure of the extent to which experimental manipulations affect the fine motor abilities of the hindpaws. In the ladder walk test, the subjects were required to cross a horizontal ladder $(20 \mathrm{~cm}$ wide; 37 rungs at $2.5 \mathrm{~cm}$ spacing) to reach the black box. Using post hoc frame-by-frame video analyses, we then recorded how many times the subjects did not successfully place their hindpaws (their paws slipped between the rungs).
Subjects that failed to plantar place on the ladder were given a maximum score of 22 footslips.

\section{Histology}

At the end of behavioral testing, subjects were deeply anesthetized (100 $\mathrm{mg} \mathrm{kg}^{-1}$ of beuthanasia, intraperitoneally) and perfused intracardially with $4 \%$ paraformaldehyde. A 1 -cm-long segment of the spinal cord that included the lesion center was taken and prepared for cryostat sectioning. The tissue was sectioned coronally $(20 \mu \mathrm{m})$ and every tenth slice was preserved for staining. All sections were stained with cresyl violet for Nissl substance and luxol fast blue for myelin. ${ }^{33,34}$

The total cross-sectional area of the cord and spared tissue was assessed at the lesion center using Neurolucida software (MBF Bioscience, Williston, VT, USA). Sections $\pm 600,1200$ and $1800 \mu \mathrm{m}$ from the lesion center (rostral and caudal) were also traced and analyzed. Four indices of lesion magnitude were derived: lesion, residual gray matter, residual white matter and width. To determine the area of lesion, an observer who was blind to the experimental treatments traced around the boundaries of cystic formations and areas of dense gliosis. ${ }^{27}$ Nissl-stained areas that contained neurons and glia of approximately normal densities denoted residual gray matter. White matter was judged spared in myelin-stained areas lacking dense gliosis and swollen fibers. The total area of each cross-section was derived by summing the areas of damage and gray and white matter. Width was determined from the most lateral points across the transverse plane. These analyses yielded six parameters for each section: white matter area, gray matter area, spared tissue (white+gray), damaged tissue area, net area (white+gray+damage) and section width.

To control for variability in the section area across subjects, we applied a correction factor derived from standard undamaged cord sections, taken from age-matched controls. This correction factor is based on section widths and is multiplied by all area measurements to standardize area across analyses. ${ }^{35}$ By standardizing area across sections, we were able to estimate the degree to which tissue is 'missing' (that is, tissue loss from atrophy, necrosis or apoptosis). An accurate assessment of the degree to which a treatment has impacted, or lesioned, the cord includes both the remaining 'damaged' tissue, as well as resolved lesioned areas. When we sum the amount of 'missing' tissue and the measured 'damaged' area, we can derive an index of the relative lesion (\% relative lesion) in each section that is comparable across sections. We can also compute the relative percent of gray and white matter remaining in each section, relative to intact controls. These measures are highly correlated with various measures of behavioral performance including BBB locomotor scores, recovery of bladder function and reactivity to shock. ${ }^{35}$

\section{Statistical analysis}

Changes from baseline scores (Reactivity after drug-Reactivity prior to drug) were used to assess the analgesic efficacy of the specific opioid receptor agonists. The scores were analyzed using analysis of variance (ANOVA), with a Duncan correction for post hoc tests. Scores were also subjected to trend analyses (polynomial regressions for linear and quadratic contrasts) to characterize dosedependent changes in behavior. Individual dose groups were further evaluated using paired $t$-tests.

In experiments with a continuous independent variable (for example, recovery of locomotor function across days), mixed-design ANOVAs were used. Because pre-treatment locomotor performance, assessed with the BBB scale, can account for a large variance in recovery across subjects, analysis of covariance was also used when appropriate (for example, when day 1 scores were a significant covariant). Significant between-subject differences were further analyzed by comparing group means using Duncan's New Multiple Range Test $(P<0.05)$. Group differences on dichotomous variables (for example, autophagia) were evaluated using chi-square probability tests. This test allows for comparisons of simple $(2 \times 2)$ frequency tables with relatively small samples.

\section{Statement of ethics}

We certify that all applicable institutional and governmental regulations concerning the ethical use of animals were followed during the course of this research. 
a

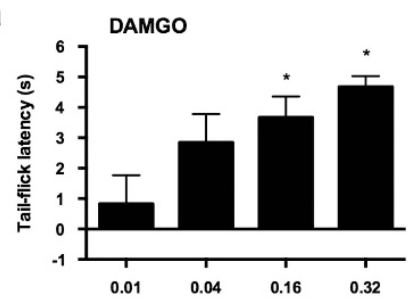

e

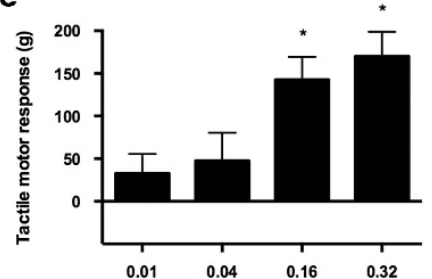

i
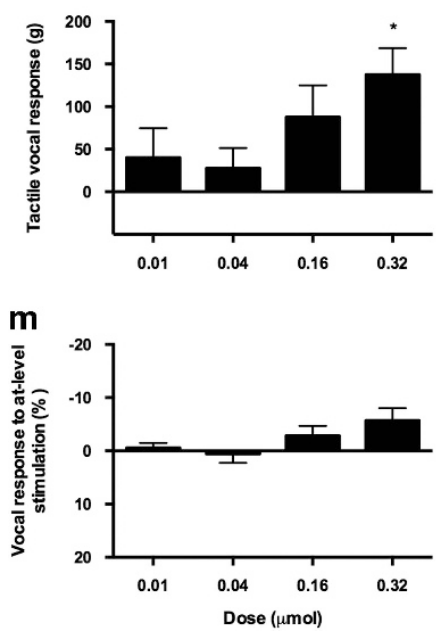

b

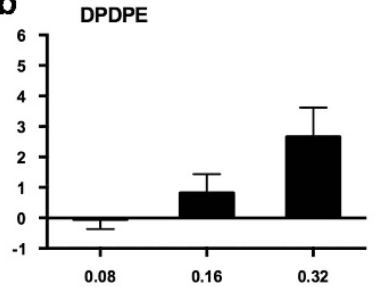

f

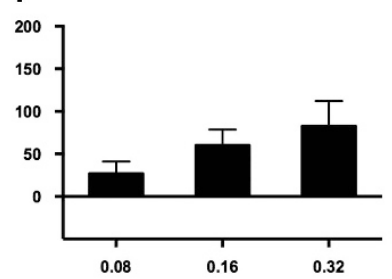

j
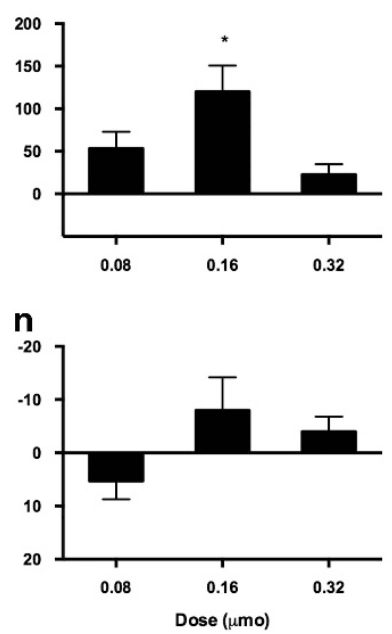

c

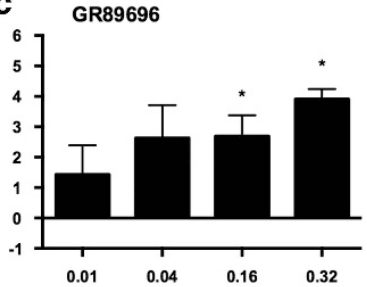

g

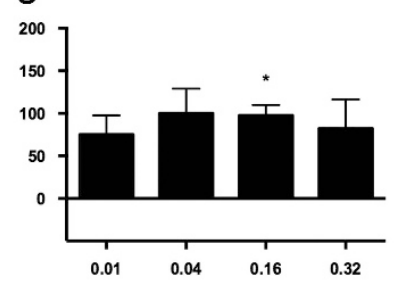

k
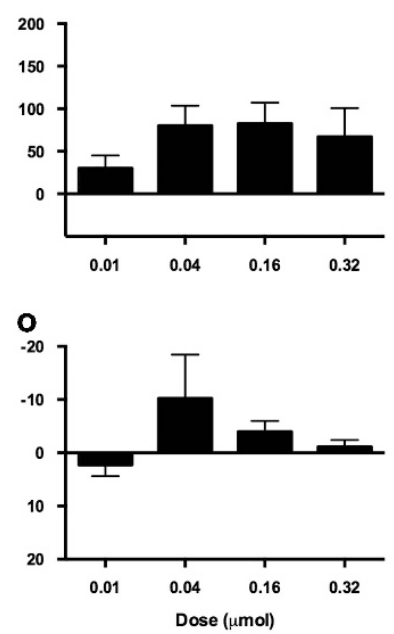

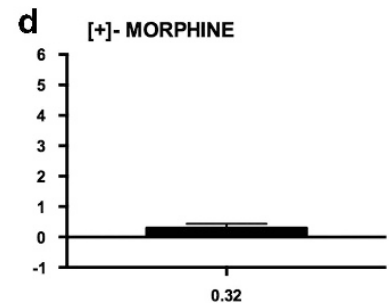

h

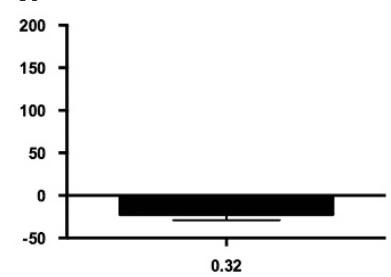

I
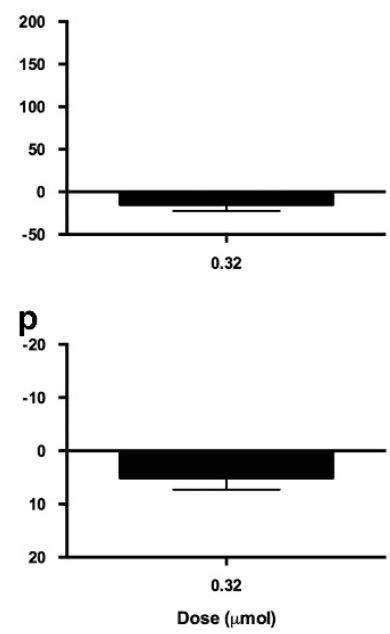

Figure 1 Analgesic efficacy of intrathecal opioid receptor agonists. These graphs depict the effects of a single, intrathecal administration of DAMGO (a, e, i, m), DPDPE (b, f, j, n), GR89696 (c, g, k, o) or [+]- morphine (d, h, l, p) on sensory reactivity. The analgesic efficacy of each specific opioid receptor agonist was determined by comparing change from baseline scores on tests of thermal (a-d) and mechanical reactivity (motor (e-h) and vocal (i-l) thresholds). At-level pain was also assessed using the girdle test $(\mathbf{m}-\mathbf{p}) .{ }^{*} P<0.05$.

\section{RESULTS}

Experiment 1: analgesic efficacy

Drug administration took place $24 \mathrm{~h}$ following surgery. After baseline motor and sensory assessments, rats were assigned to treatment conditions that were balanced across BBB scores. Each subject then received a single dose of a specific agonist. For the assessment of analgesic efficacy, a dose-response curve was generated for each agonist beginning with a molar concentration equivalent to an effective dose of morphine $(90 \mu \mathrm{g}$ or $0.32 \mu \mathrm{mol})$, as established in previous studies. ${ }^{4-6}$ Subsequent doses were chosen based on the analgesia observed.

Experiment 1A: analgesic efficacy of DAMGO. Similar to the effects of intrathecal morphine administration, DAMGO produced strong analgesia for all measures of nociceptive reactivity (Figure 1). In the tail flick test, the latency to move the tail away from the stimulus increased following drug administration at all doses tested. Although approaching significance, an ANOVA on the change from baseline values did not detect any differences across groups $(F(3,12)=3.42$, $P=0.053)$. A trend analysis, however, showed a significant linear effect, with analgesic efficacy increasing as doses increased
$(F(1,12)=9.81, P<0.05)$. Individual paired $t$-tests showed significantly different changes in response latency relative to baseline values at the highest doses, $0.16 \mu \mathrm{mol}(t=-4.615, P<0.05)$ and $0.32 \mu \mathrm{mol}$ $(t=-11.55, P<0.05)$. In fact, subjects that received $0.32 \mu \mathrm{mol}$ of DAMGO, a dose commensurate with an effective dose of morphine, did not flick their tail at all during presentation of the heat stimulus (the test was automatically terminated at $8 \mathrm{~s}$ to prevent tissue injury).

To verify the effectiveness of drug treatment, both spinal (motor) and supraspinal (vocal) measures of nociceptive reactivity were also recorded during von Frey stimulation. The results demonstrated significant differences across doses for motor $(F(3,12)=4.39$, $P<0.05)$ but not vocal $(F(3,12)=1.83, P>0.05)$ responses (Figure 1). Trend analyses revealed a significant linear effect for motor reactivity $(F(1,12)=12.11, P<0.05)$ but only approached significance for vocal reactivity $(F(1,12)=4.52, P=0.055)$. As in the tail flick test, individual $t$-tests showed significant effects of DAMGO treatment at the highest doses. Compared with baseline, significantly increased thresholds were observed at $0.16 \mu \mathrm{mol}(t=-4.57, P<0.05)$ and $0.32 \mu \mathrm{mol}(t=-5.09, P<0.05)$ for motor and at $0.32 \mu \mathrm{mol}(t=-3.83$, $P<0.05)$ for vocal responses. 
There were no significant differences across doses for girdle reactivity $(F(3,12)=1.80, P>0.05)$. As shown in Figure 1, although there was a tendency for decreased reactivity in subjects treated with the highest doses of DAMGO $(0.32$ and $0.16 \mu \mathrm{mol})$, a trend analysis did not yield a significant effect $(F=4.16, P=0.06)$.

Experiment 1B: analgesic efficacy of DPDPE. Administration of DPDPE, a selective agonist for the DOR, produced mild analgesia (Figure 1). In the tail flick test, response latency increased at higher doses $(0.16$ and $0.32 \mu \mathrm{mol})$, but an ANOVA on change from baseline values did not detect any significant differences across groups $(F(2,8)=2.53, P>0.05)$. Trend analyses showed that a linear effect approached but did not reach significance $(F(2,8)=2.53, P>0.059)$. Furthermore, no significant pre- to post-treatment changes were observed using individual $t$-tests. As opposed to the effects of DAMGO, even the highest dose of DPDPE $(0.32 \mu \mathrm{mol})$ failed to completely abolish the tail flick response.

Similarly, no significant differences across doses were observed on motor $(F(2,8)=0.993, P>0.05)$ or vocal $(F(2,8)=3.73, P>0.05)$ responses using the von Frey test. Individual $t$-tests, however, showed that DPDPE significantly increased the threshold for vocalization at the $0.16 \mu \mathrm{mol}(t=-3.37, P<0.05)$, but not the $0.32 \mu \mathrm{mol}$, dose. No effects on girdle reactivity were observed after DPDPE administration $(F(2,8)=1.44, P>0.05)$.

Experiment 1C: analgesic efficacy of GR89696. Similar to DAMGO, the KOR agonist produced a strong analgesic response on the tests of thermal and mechanical reactivity (Figure 1). Subjects treated with GR89696 showed increased latencies on the tail flick test across all

\section{a}

Locomotor Recovery
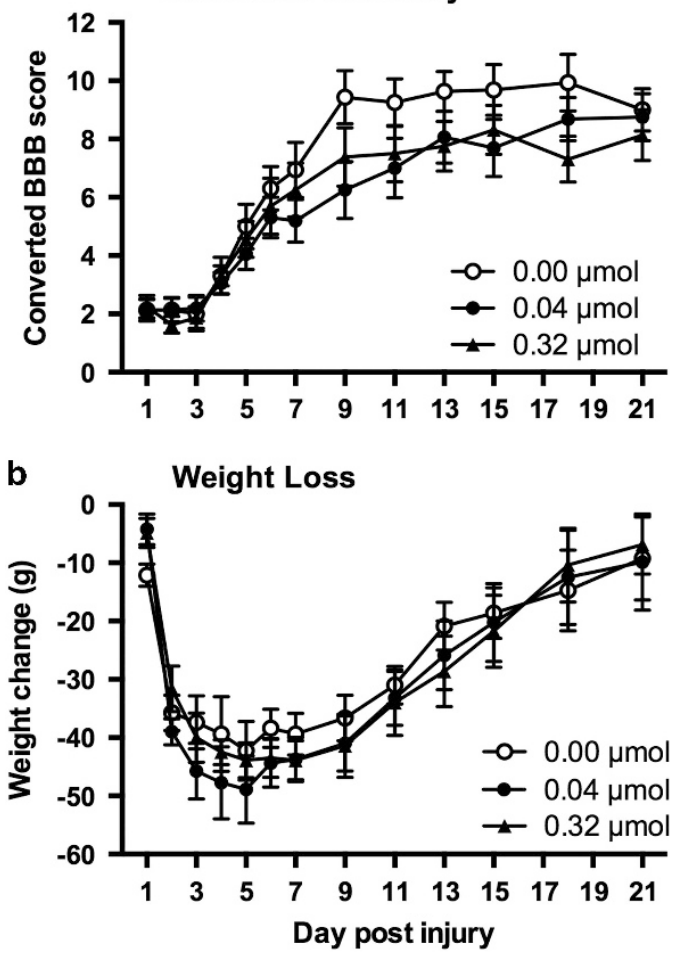

Figure 2 Effects of intrathecal DAMGO administration on recovery. Subjects were monitored for 21 days following a moderate contusion $\mathrm{SCl}$. Intrathecal administration of DAMGO, on day 1 post injury, did not affect locomotor recovery (a). Similarly, DAMGO administration did not affect weight gain across the 21-day recovery period (b). doses, when compared with baseline values. The highest dose administered $(0.32 \mu \mathrm{mol})$ resulted in complete analgesia. Although no significant differences were observed across the doses using ANOVAs $(F(3,12)=1.15, P>0.05)$, individual $t$-tests showed a significant effect of treatment at the highest doses, $0.16 \mu \mathrm{mol}$ $(t=-3.38, P<0.05)$ and $0.32 \mu \mathrm{mol}(t=-10.13, P<0.05)$, when compared with pre-treatment values.

On the von Frey test of tactile reactivity, GR89696 administration appeared to raise motor and vocal response thresholds when compared with pre-treatment values (Figure 1). As with the tail flick test, no statistically significant differences were observed across doses for either motor $(F(3,12)=0.16, P>0.05)$ or vocal $(F(3,12)=0.70$, $P>0.05)$ responses. Individual $t$-tests indicated that $0.16 \mu \mathrm{mol}$ of GR89696, however, significantly increased the threshold for motor reactivity at $30 \mathrm{~min}$ post treatment $(t=-6.79, P<0.05)$.

No effects on girdle reactivity were observed after treatment with GR89696 $(F(3,12)=1.08, P>0.05)$. Interestingly, however, in addition to analgesia, subjects that were treated with GR89696 (irrespective of dose) displayed signs of spontaneous pain (vocalizations, writhing and agitation in the absence of external stimulation) following the intrathecal injection. As opposed to the Straub-like effects of DAMGO, subjects that received GR89696 showed continued movement while in the restraining tubes and repeated vocalizations in the absence of stimulation. This behavior was not exhibited by vehicle-treated controls.

Experiment 1D: analgesic efficacy of [+]- morphine. Selective binding to non-classic opioid receptors, using the unnatural $[+]$ - enantiomer of morphine, did not result in analgesia (Figure 1). A starting dose of $0.32 \mu \mathrm{mol}$, which was effective for all of the classic opioid receptor agonists, did not produce analgesia on any of the tests. There were no significant differences between pre- and post-treatment scores on the tail-flick test $(t=-1.83, P>0.05)$ or on motor $(t=3.00, P>0.05)$ or vocal $(t=1.73, P>0.05)$ reactivity to mechanical stimuli. Similarly, no effects were observed for responses to at-level stimulation using the girdle test $(t=-2.03, P>0.05)$. As $[+]$ - morphine did not show any analgesic efficacy at the highest dose in any of these behavioral tests, lower doses were not tested.

\section{Experiment 2: recovery of function}

To assess the long-term effects of opioid receptor activation after SCI, subjects were also administered a single intrathecal dose of DAMGO, GR89696 or [+]- morphine $24 \mathrm{~h}$ following contusion and monitored for a 21-day recovery period. For these experiments, low and high doses were chosen on the basis of the results of Experiment 1 (only the $0.32 \mu \mathrm{mol}$ dose was tested in the case of [+]- morphine). As the literature does not point to a detrimental role of DOR activation, and because of its limited analgesic profile (see Figure 1), the long-term effects of DPDPE administration were not assessed.

Experiment 2A: effects of DAMGO on recovery following SCI. As can be seen in Figure 2a, administration of DAMGO did not significantly affect the recovery of locomotor function at any of the doses tested. Locomotor scores collected before treatment on day 1 did not differ across dose groups $(F(2,21)=0.03, P>0.05)$. Mean BBB scores on day 1 ranged from $2.13 \pm 0.41$, for subjects treated with vehicle, to $2.25 \pm 0.41$, for the $0.32 \mu \mathrm{mol}$ dose group. A mixed-design ANOVA also showed that there were no significant differences between the groups across the recovery period $(F(2,21)=0.33, P>0.05)$. Motor recovery was further evaluated at the end of the 21-day recovery period using the tapered beam and ladder walk tests. Treatment with 
a

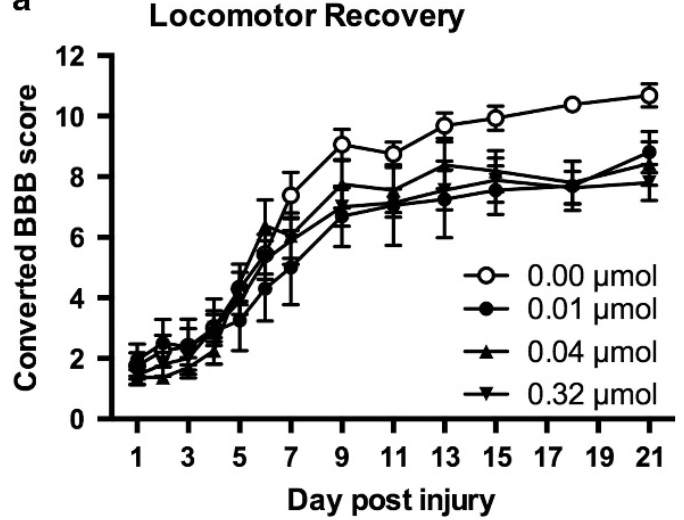

b

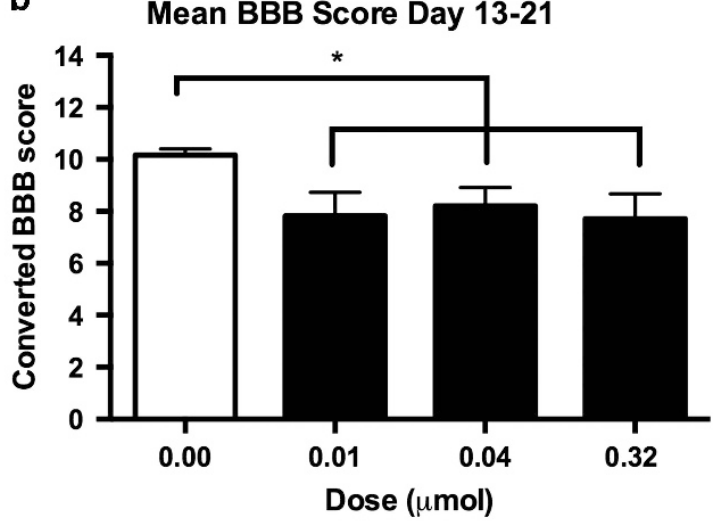

d

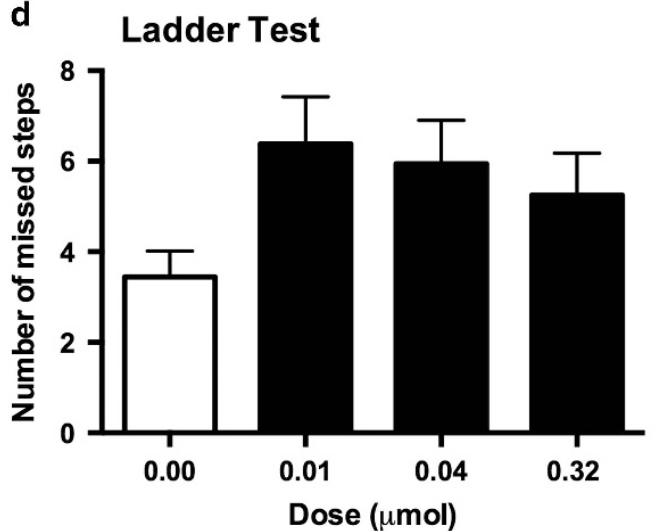

se (umol) c Tapered Beam Test

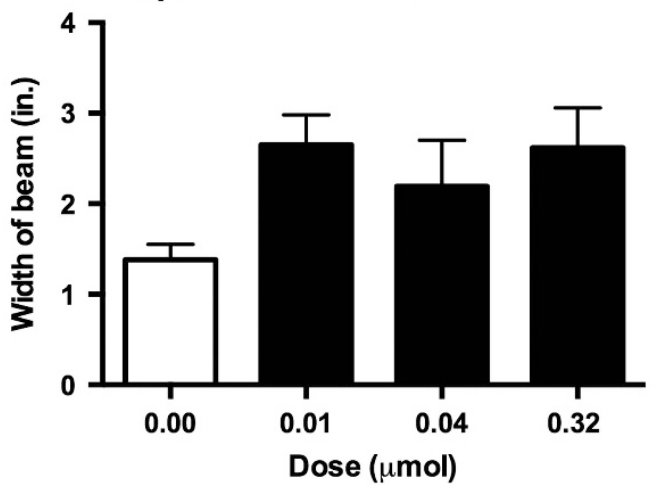

Figure 3 Effects of intrathecal GR89696 administration on recovery. Intrathecal administration of GR89696 significantly undermined the recovery of locomotor function after SCl, irrespective of the dose administered (a). In comparison with vehicle-treated controls, subjects that received GR89696 displayed significantly lower BBB scores on days 13-21 post injury (b). Vehicle-treated subjects also outperformed subjects treated with GR89696 in the tapered beam (c) and ladder (d) tests, although these differences did not reach statistical significance. ${ }^{*} P<0.05$.

DAMGO did not have any significant effect on either beam $((F(2,21)=0.60, P>0.05)$ or ladder performance $(F(2,21)=1.56$, $P>0.05)$.

Sensory function was assessed at the end of the 21-day recovery period using the tail-flick, von Frey and girdle tests. DAMGO did not have a significant effect on thermal reactivity $(F(2,21)=0.57$, $P>0.05)$, motor $(F(2,21)=2.51, P>0.05)$ or vocal reactivity $(F(2,21)=1.87, P>0.05)$ to a mechanical stimulus applied to the hind paws. An ANOVA, however, uncovered a main effect of drug dose on the girdle test $(F(2,21)=4.20, P<0.05)$, with the vehicle controls showing more reactivity to at-level stimulation than either the 0.04 or $0.32 \mu \mathrm{mol}$ groups. This difference, however, was based on a comparison of $1.7 \%$ vocalizations by the vehicle controls with zero vocalizations by the 0.04 and $0.32 \mu \mathrm{mol}$ groups and thus may not be functionally significant.

During the recovery period, weight was also monitored as an index of general health. To control for the variability observed in starting weight within each group, a difference score was calculated by subtracting the starting weight (weight at the day of surgery) from daily weight across recovery. As shown in Figure $2 \mathrm{~b}$, all subjects exhibited weight loss over the first week and then slowly regained weight over the subsequent weeks. The drug treatment, however, did not affect weight at any of the doses tested $(F(2,21)=0.16, P>0.05)$. Mean weight loss across recovery for subjects treated with vehicle was $28.90 \pm 1.72 \mathrm{~g}$ and $32.04 \pm 2.14 \mathrm{~g}$ for the $0.04 \mu \mathrm{mol}$ group and $30.25 \pm 1.90 \mathrm{~g}$ for the $0.32 \mu \mathrm{mol}$ group.
In addition to weight, we also recorded mortalities, autophagia, spastic hypertonia and recovery of bladder control to assess general health. In this experiment, there were no mortalities or spastic hypertonia observed in any of the treatment groups. Further, only one subject $(0.32 \mu \mathrm{mol}$ group $)$ showed signs of autophagia, and one recovered bladder function (vehicle group) across the entire experiment.

Experiment 2B: effects of GR89696 on recovery following SCI. In contrast to DAMGO, administration of GR89696 in the acute phase of SCI undermined recovery of locomotor function at all doses tested (Figures $3 \mathrm{a}$ and $\mathrm{b}$ ). Locomotor scores collected before treatment on day 1 did not differ across groups $(F(2,21)=0.40, P>0.05)$. Mean BBB scores ranged from $1.38 \pm 0.26$ for the $0.04 \mu \mathrm{mol}$ group to $1.94 \pm 0.57$ for the $0.01 \mu \mathrm{mol}$ group. There was also no main effect of drug treatment $(F(3,27)=2.00, P>0.05)$ on locomotor recovery. However, using day 1 scores as a covariate, an analysis of covariance revealed that there was a significant interaction between drug dose and BBB scores across the 21-day recovery period $(F(33,297)=1.86$, $P<0$. 05). An ANOVA comparing locomotor function from days 13 to 21 , when locomotor performances had stabilized, revealed a main effect of dose on locomotor function $(F(3,28)=3.01, P<0.05)$. As can be seen in Figure 3b, subjects treated with GR89696, irrespective of dose, displayed significantly lower levels of locomotor recovery relative to vehicle-treated controls $(P<0.05)$. Vehicle-treated controls also performed better than GR89696-treated subjects on additional tests of locomotor recovery. As shown in Figure 3, controls walked 
a

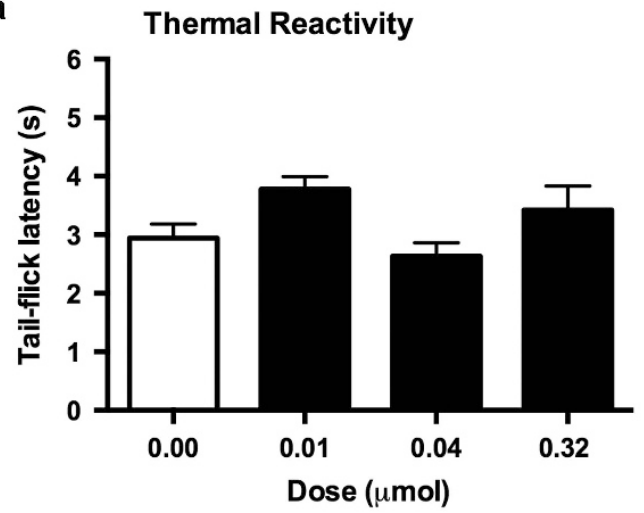

C

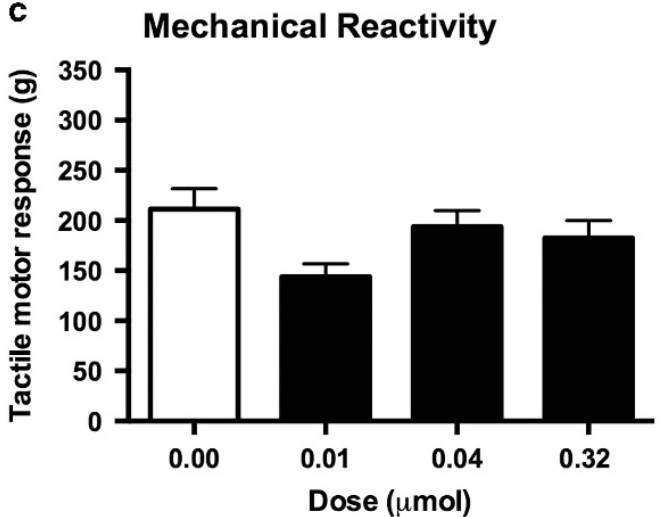

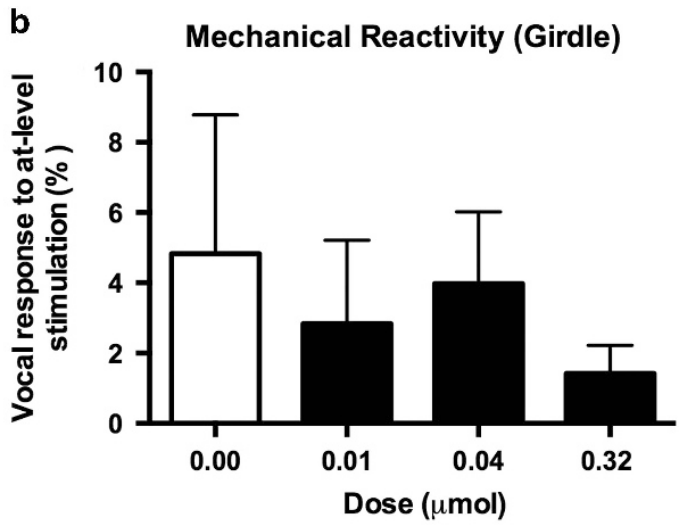

d

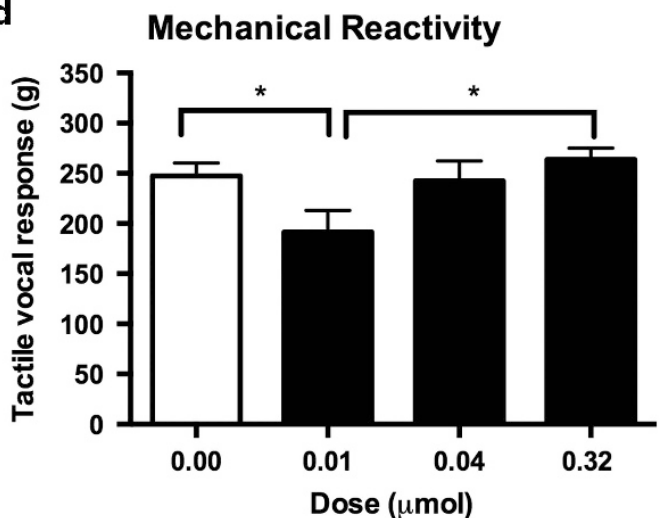

Figure 4 GR89696 did not affect the long-term recovery of sensory function. At the end of the 21-day recovery period, there were no group differences in thermal (a) or girdle (b) reactivity thresholds. Similarly, motor responses to mechanical stimulation in the von Frey test (c) did not differ across groups. Subjects that received $0.01 \mu \mathrm{mol}$ of GR89696, however, showed lower vocal thresholds to tactile stimulation in comparison with those in the $0.32 \mu \mathrm{mol}$ and control groups (d). ${ }^{*} P<0.05$.

across the narrow edge of the tapered beam with more success than experimental subjects (Figure $3 \mathrm{c}$ ) and made less errors when traversing a ladder (Figure 3d). These differences, however, did not reach statistical significance on either the beam $(F(3,28)=2.10, P>0.05)$ or the ladder walk tests $(F(3,28)=1.83, P>0.05)$.

At the end of the 21-day recovery period, tests of sensory reactivity showed that administration of GR89696 did not affect thermal reactivity $(F(3,28)=2.77, P>0.05)$, motor reactivity to tactile stimulation $(F(3,28)=2.49, P>0.05)$ or at-level allodynia assessed with the girdle test $(F(3,28)=0.29, P>0.05$; data not shown). However, as shown in Figure 4d, ANOVAs uncovered significant differences for vocal reactivity across doses $(F(3,28)=2.95, P<0.05)$, with subjects in the $0.01 \mu \mathrm{mol}$ group showing decreased reactivity thresholds when compared with subjects in the $0.32 \mu \mathrm{mol}$ and control groups.

Weight loss across recovery was unaffected by GR89696 treatment $(F(3,28)=1.09, P>0.05$; data not shown). As normally observed following SCI, all subjects showed decreased weight early after injury, which was slowly regained over time. Mean weight loss across recovery for subjects treated with vehicle was $19.60 \pm 1.60 \mathrm{~g}$ and $23.76 \pm 1.90 \mathrm{~g}$ for the $0.01 \mu \mathrm{mol}$ group, $25.28 \pm 2.04 \mathrm{~g}$ for the $0.04 \mu \mathrm{mol}$ group and $29.59 \pm 1.85 \mathrm{~g}$ for the $0.32 \mu \mathrm{mol}$ group. There were no significant effects of drug treatment on recovery of bladder control $F(3,28)=0.43, P>0.05)$. Mortality was also unaffected, with only one death recorded in the vehicle group and one in the $0.32 \mu \mathrm{mol}$ group. Only one case of spastic hypertonia was observed $(0.01 \mu \mathrm{mol}$ group) for the entire experiment. Finally, although we observed a dose-dependent increase in autophagia, this was not a statistically significant effect $\left(\chi^{2}=7.38, P>0.05\right)$.

Experiment 2C: effects of [+]-morphine on recovery following SCI. Surprisingly, administration of the unnatural [+]- enantiomer of morphine did not have any significant effects on the recovery of locomotor function (Figure 5a), despite administering a dose equivalent to the natural [-]- enantiomer of morphine previously shown to undermine recovery. ${ }^{4,6}$ Mean BBB scores collected before treatment on day 1 were $1.88 \pm 0.35$ for vehicle-treated controls and $1.81 \pm 0.38$ for $[+]$ - morphine-treated subjects and did not differ statistically $(F(1,14)=0.02, P>0.05)$. No differences in locomotor recovery emerged between the groups across the recovery period $(F(1,14)=0.20, P>0.05)$. There were also no significant differences between the groups after day 21 on either the beam $(F(1,14)=1.18$, $P>0.05)$ or the ladder $(F(1,14)=0.02, P>0.05)$ tests.

Similarly, treatment with the morphine enantiomer early after the contusion did not affect sensory reactivity after day 21 post injury (data not shown). Subjects that received [+]- morphine did not differ from their vehicle-treated counterparts on any of the sensory reactivity tests (tail flick $(F(1,14)=0.86, P>0.05)$, tactile motor $(F(1,14)=0.28, P>0.05)$, tactile vocal $(F(1,14)=1.18, P>0.05)$ and girdle $(F(1,14)=1.16, P>0.05))$. Weight loss across recovery was also unaffected by $[+]$ - morphine treatment $(F(1,14)=1.24, P>0.05$, Figure $5 b)$. On average, subjects treated with vehicle lost $23.75 \pm 1.58 \mathrm{~g}$ across recovery, whereas subjects treated with $[+]$ - morphine lost $28.55 \pm 1.67 \mathrm{~g}$ 


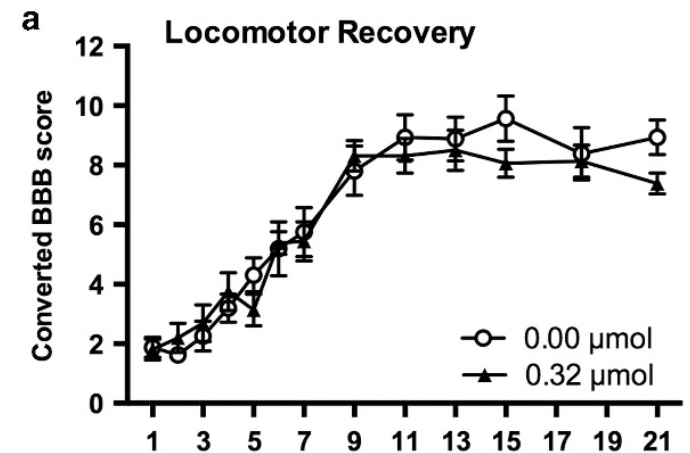

b

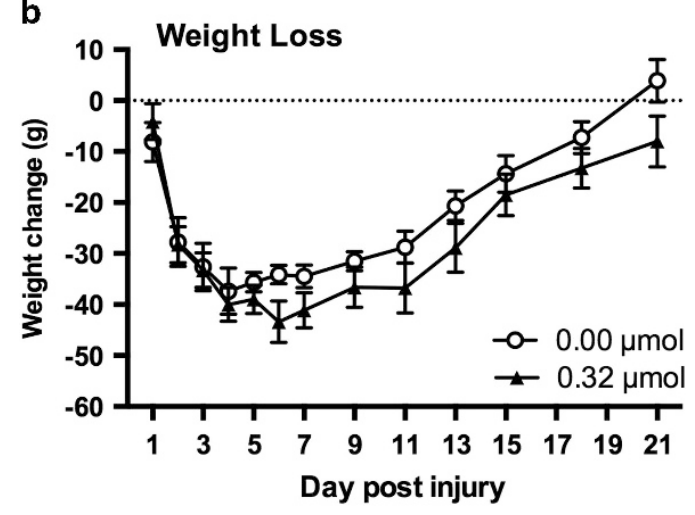

Figure 5 Effects of intrathecal [+]- morphine administration on recovery. Treatment with the unnatural [+]- enantiomer of morphine in the acute phase of $\mathrm{SCl}$ did not affect either long-term recovery of locomotor function (a) or weight (b).

Finally, we did not observe any significant effects of drug treatment on mortality (a single subject died in the vehicle group). None of the subjects recovered bladder control, and no spastic hypertonia was recorded throughout the duration of the experiment. Administration of [+]- morphine appeared to exacerbate autophagia, with $37.5 \%$ of [+]- morphine subjects demonstrating signs of self-harm, compared with $0 \%$ of vehicle-treated controls. This effect approached but did not reach statistical significance $\left(\chi^{2}=3.69, P=0.055\right)$.

\section{Histological results}

As GR89696 administration had a significant impact on locomotor recovery, we wanted to see whether the effects were due to decreased tissue sparing at the injury site. Four measures were analyzed: residual white matter, residual gray matter, tissue damage and relative lesion (damage+missing tissue). There were no effects of drug dose on any of our histological measures at the center of the lesion (Figure 6). Similarly, there were no significant effects rostral to the lesion, although a main effect of drug dose on residual gray matter approached significance $(F(2,17)=2.99, P=0.077)$. Caudally, however, we found a significant main effect of dose on residual gray matter $(F(2,15)=5.74, P<0.05)$. Post hoc analyses revealed that subjects in the $0.01 \mu \mathrm{mol}$ group had significantly less spared gray matter than subjects treated with vehicle. A main effect of drug dose also approached but did not reach significance for the measure of tissue damage caudal to the injury site $(F(2,15)=2.98, P=0.08)$. There were no significant effects on residual white matter at this level of the spinal cord.

\section{DISCUSSION}

In accordance with the literature, in this study, we showed that, following SCI, DAMGO, the selective agonist for the MOR, produced the most robust analgesia in tests of thermal and mechanical reactivity. Administration of DPDPE, a DOR-agonist, only produced modest analgesia, even at the highest doses tested. Surprisingly, treatment with GR89696 resulted in strong analgesia at higher doses, although transient agitation was also observed in subjects treated with this KOR agonist. Unfortunately, despite its analgesic efficacy, a single dose of GR89696 also significantly undermined the recovery of locomotor function, increased mechanical reactivity and decreased gray matter sparing after SCI. In fact, even the lowest dose of GR89696 replicated the negative side effects associated with morphine treatment in our previous studies, ${ }^{4,6}$ even at a dose 32 times smaller. These results indicate increased involvement of the spinal KOR system following injury and further underscore the need to re-evaluate the safety of clinically used opioids for the treatment of pain in the SCI population.

On the basis of the data presented here, we propose that the analgesic efficacy of intrathecal morphine in the SCI model ${ }^{4,6}$ is mediated by binding to the $\mu$ - and $\kappa$-opioid receptors. Although studies on opioid receptor distribution in the spinal cord support the significant contribution of the MOR to the antinociceptive effects of morphine, ${ }^{36,37}$ the results of selective activation of the KOR were unexpected. Studies have long disputed the role of the KOR in spinal analgesia. For example, in a study by Leighton and colleagues, ${ }^{38}$ intrathecal administration of three different KOR agonists (PD1 17302, U50488, U69593) failed to increase antinociception to noxious mechanical and thermal stimuli, even at doses up to $100 \mu \mathrm{g}$. Others have suggested that KOR-mediated analgesia is intensity- and stimulus-dependent, with intrathecally applied KOR ligands showing potency on tests of chemical-visceral pain but not cutaneous-thermal or electrical sensory input. ${ }^{39-41}$ Furthermore, intrathecal administration of exogenous and endogenous KOR ligands has also been associated with paralysis and flaccidity of the tail and hind limbs, effects that complicate the interpretation of analgesic tests requiring a motor response. ${ }^{38,42}$ In contrast to these studies, however, others have shown that KOR agonists can produce significant spinal analgesia. ${ }^{43,44}$ Indeed using knockout mice, Yamada et al. ${ }^{45}$ found that intrathecal administration of morphine produced analgesia in the absence of MORs by acting through spinal KORs. In our studies, the KOR agonist, GR89696, exhibited an analgesic profile comparable with morphine and the selective MOR agonist, DAMGO. Acute intrathecal administration of GR89696 increased subjects' thermal and mechanical thresholds. Furthermore, we verified that the decreased motor responses in these tests were not simply due to paralysis by recording vocal responses to stimulation. Subjects treated with GR89696 displayed increased vocal response thresholds with mechanical stimulation, indicative of analgesia. Overall, these findings point to an important role for the spinal KOR system in intrinsic pain modulation after SCI.

It is possible that distinct KOR subtypes mediate analgesia at the level of the spinal cord. Indeed, evidence for further classifying the KOR into subtypes 1,2 and 3 has emerged from binding and pharmacological studies. ${ }^{46}$ Molecular evidence, however, does not support these subdivisions. For instance, only one KOR gene has been identified, which eliminates all KOR activity upon genetic knockout. ${ }^{46}$ Instead of receptor subtypes, the different pharmacological profiles could be driven by other factors, including alternative gene splicing, posttranslational modifications, receptor dimerization and the activation of diverse effector proteins. ${ }^{47}$ From a behavioral standpoint, however, this does not negate the importance of different 

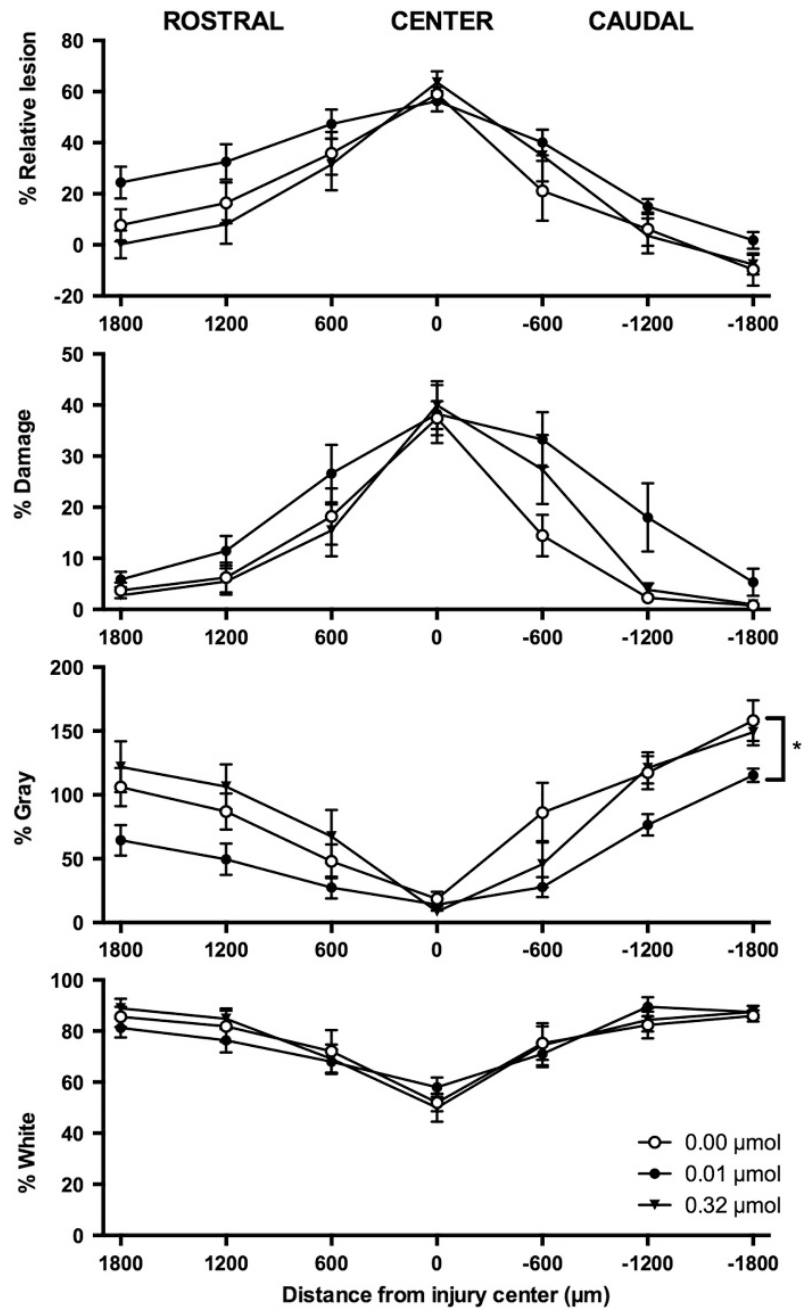

Figure 6 Effects of intrathecal GR89696 administration on tissue sparing following SCl. The dose-dependent effects of GR89696 on lesion size (relative lesion), damage, residual gray matter and residual white matter are depicted. A single $0.01 \mu \mathrm{mol}$ dose of GR89696, administered in the acute phase of $\mathrm{SCl}$, significantly decreased the amount of spared gray matter caudal to the injury center in comparison with vehicle-treated controls. ${ }^{*} P<0.05$.

pharmacologically identified receptor subtypes, especially in the area of pain research. For instance, opioid compounds thought to bind to different KOR subtypes show distinct analgesic profiles. In comparison with KOR subtype 1 (KOR1) agonists, KOR subtype 2 (KOR2) agonists administered intrathecally are more effective anti-hyperalgesic agents in inflammatory models. ${ }^{48}$ Intrathecal oxycodone also results in antinociceptive effects following nerve injury and has been proposed to act as a KOR2 agonist. ${ }^{49}$ This coincides with our findings with GR89696, which is thought to be a selective ligand for KOR2. Furthermore, these studies also point to an interaction between injury and KOR2 function.

In addition, in our study, the analgesic efficacy of intrathecal GR89696 could also reflect changes in KOR expression following injury. We know that, in the spinal cord, KOR density is not set but fluctuates in response to a variety of factors. For example, spinal KOR levels vary across the estrous cycle in rats, decreasing during diestrus. ${ }^{50}$ Alterations have also been reported following inflammation or peripheral nerve injury. ${ }^{51-53}$ The spinal KOR system also appears to undergo modifications after SCI. Studies have shown that immunoreactivity of endogenous KOR ligands increases progressively with injury severity in the spinal cord following trauma. ${ }^{54}$ Further, using $\left[{ }^{3} \mathrm{H}\right]$ ethylketocyclazocine, Krumins et al. ${ }^{55}$ showed significantly increased binding at the site of a SCI that was evident as early as $2 \mathrm{~h}$ post SCI and up to 7 days. This upregulation of KOR expression and binding may affect locomotor function. Indeed, dynorphin alone has been shown to induce paraplegia in animals, even when administered to the intact spinal cord. ${ }^{15,42}$ These findings, combined with the results presented here, implicate the KOR system in the pathophysiology of SCI.

We hypothesize that upregulated KOR expression following SCI may exacerbate secondary injury processes. Although increased KOR expression on presynaptic terminals and neurons of the dorsal horn may be responsible for greater KOR-mediated analgesia after SCI, increased KOR expression on glial cells may be related to the adverse long-term effects on locomotor and sensory recovery. For example, $\mathrm{Xu}$ et $a .^{56}$ have shown that KOR activation contributes to astrocyte proliferation after a partial sciatic nerve ligation. In this study, dynorphin knockout mice, mice with a homozygous KOR deletion and mice treated with a specific KOR antagonist (norBNI) failed to show astrocyte proliferation in the dorsal horn of the spinal cord. Conversely, cultured mouse spinal astrocytes treated with the selective KOR agonist U50488 showed increased proliferation and increased phosphor-p38 MAPK immunoreactivity. Both of these effects were blocked by administration of either norBNI or the p38 MAPK inhibitor SB 203580, suggesting that the effects of the KOR may be mediated through this signaling pathway. Importantly, intrathecal injections of SB 203580 for 7 days after partial sciatic nerve ligation reduced spinal astrocyte proliferation in vivo, an effect that correlated with decreased signs of neuropathic pain, such as allodynia and hyperalgesia. ${ }^{56}$ These findings suggest that, in the context of SCI, morphine administration could exacerbate glial reactivity by binding to KORs on these cells.

Indeed, extensive in vitro and in vivo evidence suggests that opioid administration results in the activation of glial cells and the release of pro-inflammatory cytokines. ${ }^{24,25,57-60}$ For instance, lumbar dorsal spinal cord sections show significant increases in the release of IL-1 $\beta$, IL-6, fractalkine, GRO/KC, MIP- $1 \alpha$, MCP- 1 and TNF- $\alpha$ following 180 min of incubation with $100 \mu \mathrm{M}$ morphine compared with media alone. ${ }^{24}$ Similarly, in vivo, increases in IL- $1 \alpha$, IL- $1 \beta$, IL- 6 and TNF- $\alpha$ have been demonstrated after 7 days of intrathecal morphine. ${ }^{24}$ We have also previously shown that, in the SCI model, morphine administration results in increased expression of the pro-inflammatory cytokines IL- $1 \beta$ and IL- 6 at the injury site. ${ }^{4}$ Although we originally suggested that these effects may result from morphine binding to nonclassic opioid receptors, it is possible that this could also be due to the activation of KORs on glial cells. Functionally, this could substantially increase the already highly inflammatory environment, leading to excitotoxic cell death, a possibility that could explain our histological results. Furthermore, glial activation at the level of the spinal cord might also contribute to central sensitization, a mechanism thought to underlie pathological pain. ${ }^{61}$

Finally, although not assessed in the current study, the NMDA receptor may also have a role in the morphine-induced attenuation of functional recovery. An interaction between opioids and NMDA receptors in the pathophysiology of SCI has been previously described in the literature. In fact, the detrimental effects of the endogenous opioid dynorphin appear to be mediated by both KORs and NMDA receptors. ${ }^{62-64}$ Chronic morphine administration is also associated with neuronal apoptosis, potentially through an NMDA-regulated pathway. Mao et al., ${ }^{13}$ for example, found increased protein expression 
of caspase- 3 and Bax pro-apoptotic elements, accompanied by a decrease in the anti-apoptotic Bcl-2 protein, in the dorsal horn of rats after prolonged morphine treatment. Notably, neuronal apoptosis was blocked by the administration of MK-801, an NMDA receptor antagonist. This, combined with the downregulation of spinal glutamate transporters observed after chronic morphine administration, ${ }^{12}$ further suggests that increased cell loss may be the result of the highly toxic excitatory environment. In our model, using MK-801 as an adjuvant to intrathecal morphine may protect against the long-term adverse effects on recovery of function and should be further investigated.

In conclusion, we have shown that activation of the KOR with GR89696 is sufficient to undermine locomotor recovery after SCI. By contrast, neither DAMGO nor [+]- morphine affected the recovery. On the basis of these data, we hypothesize that the adverse effects of morphine on the recovery of locomotor function are mediated by the KOR system. Now, given that frequently prescribed analgesics like oxycodone act through the KOR receptor system, it is paramount that we identify the mechanisms mediating the adverse effects of KOR activation after SCI. Indeed, our data demonstrate that even very low doses of KOR ligands may undermine recovery, as shown by the attenuation of function observed at a dose 32-fold lower than an effective dose of morphine. Finally, the role of the MOR and non-classic opioid receptors should not be discounted. Although we did not observe any effects of DAMGO or [+]- morphine after a single administration, it is possible that detrimental effects may emerge with prolonged administration. ${ }^{65}$ Ultimately, elucidating the molecular mechanisms underlying the effects of morphine, and other opioids, is imperative to develop pharmacological interventions that are both safe and efficacious in a clinical setting.

\section{DATA ARCHIVING}

There were no data to deposit.

\section{CONFLICT OF INTEREST}

The authors declare no conflict of interest.

\section{ACKNOWLEDGEMENTS}

We thank Eric Bancroft and Alejandro R Aceves for their comments on a previous version of this manuscript and the NIDA Drug Supply Program for their generous support. The NIDA Drug Supply Program generously provided the $[+]$ - morphine enantiomer. This work was funded by grant DA31197 to MA Hook.

1 Consortium for Spinal Cord Medicine. Early acute management in adults with spinal cord injury: a clinical practice guideline for health-care professionals. J Spinal Cord Med 2008; 31: 408-479.

2 Neighbor ML, Honner S, Kohn MA. Factors affecting emergency department opioid administration to severely injured patients. Acad Emerg Med 2004; 11: 1290-1296.

3 Woller SA, Moreno GL, Hart N, Wellman PJ, Grau JW, Hook MA. Analgesia or addiction?: implications for morphine use after spinal cord injury. I Neurotrauma 2012; 29: 1650-1662.

4 Hook MA, Washburn SN, Moreno G, Woller SA, Puga D, Lee KH et al. An IL-1 receptor antagonist blocks a morphine-induced attenuation of locomotor recovery after spinal cord injury. Brain Behav Immun 2011; 25: 349-359.

5 Hook MA, Liu GT, Washburn SN, Ferguson AR, Bopp AC, Huie JR et al. The impact of morphine after a spinal cord injury. Behav Brain Res 2007; 179: 281-293.

6 Hook MA, Moreno G, Woller S, Puga D, Hoy K Jr, Balden R et al. Intrathecal morphine attenuates recovery of function after a spinal cord injury. J Neurotrauma 2009; 26: 741-752.

7 Woller SA, Malik JS, Aceves M, Hook MA. Morphine self-administration following spinal cord injury. J Neurotrauma 2014; 31: 1570-1583.
8 Kristensen K, Christensen CB, Christrup LL. The mu 1, mu 2, delta, kappa opioid receptor binding profiles of methadone stereoisomers and morphine. Life Sci 1994; 56: 45-50.

9 Wang X, Loram LC, Ramos K, de Jesus AJ, Thomas J, Cheng K et al. Morphine activates neuroinflammation in a manner parallel to endotoxin. Proc Natl Acad Sci USA 2012; 109: 6325-6330.

10 Chen L, Huang L-YM. Protein kinase C reduces Mg2+ block of NMDA-receptor channels as a mechanism of modulation. Nature 1992; 356: 521-523.

11 Yang L, Wang S, Sung B, Lim G, Mao J. Morphine induces ubiquitin-proteasome activity and glutamate transporter degradation. J Biol Chem 2008; 283: 21703-21713.

12 Mao J, Sung B, Ji R-R, Lim G. Chronic morphine induces downregulation of spinal glutamate transporters: implications in morphine tolerance and abnormal pain sensitivity. J Neurosci 2002; 22: 8312-8323.

13 Mao J, Sung B, Ji R-R, Lim G. Neuronal apoptosis associated with morphine tolerance: evidence for an opioid-induced neurotoxic mechanism. J Neurosci 2002; 22: 7650-7661.

14 Woolf CJ, Thompson SW. The induction and maintenance of central sensitization is dependent on N-methyl-D-aspartic acid receptor activation; implications for the treatment of post-injury pain hypersensitivity states. Pain 1991; 44: 293-299.

15 Faden Al, Jacobs TP. Dynorphin induces partially reversible paraplegia in the rat. Eur J Pharmacol 1983; 91: 321-324.

16 Faden Al, Takemori A, Portoghese P. $\kappa$-Selective opiate antagonist nor-binaltorphimine improves outcome after traumatic spinal cord injury in rats. Cent Nerv Syst Trauma 1987; 4: 227-234.

17 Watkins LR, Hutchinson MR, Rice KC, Maier SF. The "toll" of opioid-induced glial activation: improving the clinical efficacy of opioids by targeting glia. Trends Pharmacol Sci 2009; 30: 581-591.

18 Tawfik VL, Lacroix-Fralish ML, Nutile-McMenemy N, DeLeo JA. Transcriptional and translational regulation of glial activation by morphine in a rodent model of neuropathic pain. J Pharmacol Exp Ther 2005; 313: 1239-1247.

19 Hutchinson MR, Zhang Y, Brown K, Coats BD, Shridhar M, Sholar PW et al. Non-stereoselective reversal of neuropathic pain by naloxone and naltrexone: involvement of toll-like receptor 4 (TLR4). Eur J Neurosci 2008; 28: 20-29.

20 Hutchinson MR, Bland ST, Johnson KW, Rice KC, Maier SF, Watkins LR. Opioid-induced glial activation: mechanisms of activation and implications for opioid analgesia, dependence, and reward. ScientificWorldJournal 2007; 7: 98-111.

21 Hutchinson MR, Zhang Y, Shridhar M, Evans JH, Buchanan MM, Zhao TX et al. Evidence that opioids may have toll-like receptor 4 and MD-2 effects. Brain Behav Immun 2010; 24: 83-95.

22 Lewis SS, Hutchinson MR, Rezvani N, Loram LC, Zhang Y, Maier SF et al. Evidence that intrathecal morphine-3-glucuronide may cause pain enhancement via toll-like

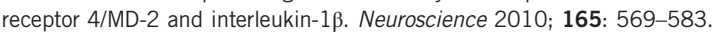

23 Hutchinson MR, Lewis SS, Coats BD, Rezvani N, Zhang Y, Wieseler JL et al. Possible involvement of toll-like receptor 4/myeloid differentiation factor-2 activity of opioid inactive isomers causes spinal proinflammation and related behavioral consequences. Neuroscience 2010; 167: 880-893.

24 Hutchinson MR, Coats BD, Lewis SS, Zhang $\mathrm{Y}$, Sprunger DB, Rezvani $\mathrm{N}$ et al. Proinflammatory cytokines oppose opioid-induced acute and chronic analgesia. Brain Behav Immun 2008; 22: 1178-1189.

25 Johnston IN, Milligan ED, Wieseler-Frank J, Frank MG, Zapata V, Campisi J et al. A role for proinflammatory cytokines and fractalkine in analgesia, tolerance, and subsequent pain facilitation induced by chronic intrathecal morphine. J Neurosci 2004; 24: 7353-7365.

26 Christensen MD, Hulsebosch CE. Chronic central pain after spinal cord injury. J Neurotrauma 1997; 14: 517-537.

27 Basso DM, Beattie MS, Bresnahan JC. A sensitive and reliable locomotor rating scale for open field testing in rats. J Neurotrauma 1995; 12: 1-21.

28 Ferguson AR, Hook MA, Garcia G, Bresnahan JC, Beattie MS, Grau JW. A simple post hoc transformation that improves the metric properties of the BBB scale for rats with moderate to severe spinal cord injury. J Neurotrauma 2004; 21: 1601-1613.

29 Soblosky JS, Colgin LL, Chorney-Lane D, Davidson JF, Carey ME. Some functional recovery and behavioral sparing occurs independent of task-specific practice after injury to the rat's sensorimotor cortex. Behav Brain Res 1997; 89: 51-59.

30 Hicks SP, D'Amato CJ. Motor-sensory cortex-corticospinal system and developing locomotion and placing in rats. Am J Anat 1975; 143: 1-42.

31 von Euler M, Akesson E, Samuelsson EB, Seiger A, Sundstrom E. Motor performance score: a new algorithm for accurate behavioral testing of spinal cord injury in rats. Exp Neurol 1996; 137: 242-254.

32 von Euler M, Seiger A, Sundstrom E. Clip compression injury in the spinal cord: a correlative study of neurological and morphological alterations. Exp Neurol 1997; 145: 502-510.

33 Beattie MS. Anatomic and behavioral outcome after spinal cord injury produced by a displacement controlled impact device. J Neurotrauma 1992; 9: 157-159.

34 Behrmann DL, Bresnahan JC, Beattie MS, Shah BR. Spinal cord injury produced by consistent mechanical displacement of the cord in rats: behavioral and histologic analysis. J Neurotrauma 1992; 9: 197-217.

35 Grau JW, Washburn SN, Hook MA, Ferguson AR, Crown ED, Garcia G et al. Uncontrollable stimulation undermines recovery after spinal cord injury. J Neurotrauma 2004; 21: 1795-1817.

36 Arvidsson U, Riedl M, Chakrabarti S, Lee J-H, Nakano AH, Dado R et al. Distribution and targeting of a mu-opioid receptor (MOR1) in brain and spinal cord. J Neurosci 1995; 15: 3328-3341. 
37 Mansour A, Fox CA, Burke S, Akil H, Watson SJ. Immunohistochemical localization of the cloned $\mu$ opioid receptor in the rat CNS. J Chem Neuroanat 1995; 8: 283-305.

38 Leighton G, Rodriguez R, Hill R, Hughes J. kappa-Opioid agonists produce antinociception after iv and icv but not intrathecal administration in the rat. Br J Pharmacol 1988; 93: 553.

39 Millan M. Kappa-opioid receptor-mediated antinociception in the rat. I. Comparative actions of mu-and kappa-opioids against noxious thermal, pressure and electrical stimuli. J Pharmacol Exp Ther 1989; 251: 334-341.

40 Schmauss C. Spinal $\kappa$-opioid receptor-mediated antinociception is stimulus-specific. Eur J Pharmacol 1987; 137: 197-205.

41 Schmauss C, Yaksh TL. In vivo studies on spinal opiate receptor systems mediating antinociception. II. Pharmacological profiles suggesting a differential association of mu, delta and kappa receptors with visceral chemical and cutaneous thermal stimuli in the rat. J Pharmacol Exp Ther 1984; 228: 1-12.

42 Herman BH, Goldstein A. Antinociception and paralysis induced by intrathecal dynorphin A. J Pharmacol Exp Ther 1985; 232: 27-32.

43 Piercey M, Lahti R, Schroeder L, Einspahr F, Barsuhn C. U-50488H, a pure kappa receptor agonist with spinal analgesic loci in the mouse. Life Sci 1982; 31: 1197-1200.

44 Lahti R, VonVoigtlander P, Barsuhn C. Properties of a selective kappa agonist, U-50,488 H. Life Sci 1982; 31: 2257-2260.

45 Yamada H, Shimoyama N, Sora I, Uhl GR, Fukuda Y, Moriya H et al. Morphine can produce analgesia via spinal kappa opioid receptors in the absence of mu opioid receptors. Brain Res 2006; 1083: 61-69.

46 Dietis N, Rowbotham D, Lambert D. Opioid receptor subtypes: fact or artifact?. $\mathrm{Br} \mathrm{J}$ Anaesth 2011; 107: 8-18.

47 Law P-Y, Reggio PH, Loh HH. Opioid receptors: toward separation of analgesic from undesirable effects. Trends Biochem Sci 2013; 38: 275-282.

48 Ho J, Mannes AJ, Dubner R, Caudle RM. Putative kappa-2 opioid agonists are antihyperalgesic in a rat model of inflammation. J Pharmacol Exp Ther 1997; 281. 136-141.

49 Nielsen CK, Ross FB, Lotfipour S, Saini KS, Edwards SR, Smith MT. Oxycodone and morphine have distinctly different pharmacological profiles: radioligand binding and behavioural studies in two rat models of neuropathic pain. Pain 2007; 132 289-300.

50 Chang PC, Aicher SA, Drake CT. Kappa opioid receptors in rat spinal cord vary across the estrous cycle. Brain Res 2000; 861: 168-172.

51 Besse D, Lombard M, Zajac J, Roques B, Besson J. Pre-and postsynaptic distribution of $\mu, \delta$ and $\kappa$ opioid receptors in the superficial layers of the cervical dorsal horn of the rat spinal cord. Brain Res 1990; 521: 15-22.
52 Besse D, Weil-Fugazza J, Lombard M-C, Butler SH, Besson J-M. Monoarthritis induces complex changes in $\mu$-, $\delta$-and $\kappa$-opioid binding sites in the superficial dorsal horn of the rat spinal cord. Eur J Pharmacol 1992; 223: 123-131.

53 Maekawa K, Minami M, Masuda T, Satoh M. Expression of $\mu$-and $\kappa^{-}$, but not $\delta$-, opioid receptor mRNAs is enhanced in the spinal dorsal horn of the arthritic rats. Pain 1996; 64: 365-371.

54 Faden Al, Molioneaux CJ, Rosenberger JG, Jacobs TP, Cox BM. Endogenous opioid immunoreactivity in rat spinal cord following traumatic injury. Ann Neurol 1985; 17: 386-390.

55 Krumins SA, Faden Al. Traumatic injury alters opiate receptor binding in rat spinal cord. Ann Neurol 1986; 19: 498-501.

56 Xu M, Bruchas MR, Ippolito DL, Gendron L, Chavkin C. Sciatic nerve ligation-induced proliferation of spinal cord astrocytes is mediated by $\kappa$ opioid activation of p38 mitogenactivated protein kinase. J Neurosci 2007; 27: 2570-2581.

57 Raghavendra V, Rutkowski MD, DeLeo JA. The role of spinal neuroimmune activation in morphine tolerance/hyperalgesia in neuropathic and sham-operated rats. $J$ Neurosci 2002; 22: 9980-9989.

58 Raghavendra V, Tanga FY, DeLeo JA. Attenuation of morphine tolerance, withdrawalinduced hyperalgesia, and associated spinal inflammatory immune responses by propentofylline in rats. Neuropsychopharmacology 2004; 29: 327-334.

59 Song $\mathrm{P}$, Zhao Z-Q. The involvement of glial cells in the development of morphine tolerance. Neurosci Res 2001; 39: 281-286.

60 Cui Y, Chen Y, Zhi J-L, Guo R-X, Feng J-Q, Chen P-X. Activation of p38 mitogenactivated protein kinase in spinal microglia mediates morphine antinociceptive tolerance. Brain Res 2006; 1069: 235-243.

$61 \mathrm{Ikeda} \mathrm{H}$, Kiritoshi T, Murase K. Contribution of microglia and astrocytes to the central sensitization, inflammatory and neuropathic pain in the juvenile rat. Mol Pain 2012; 8: 43

62 Faden Al. Opioid and nonopioid mechanisms may contribute to dynorphin's pathophysiological actions in spinal cord injury. Ann Neurol 1990; 27: 67-74.

63 Long JB, Petras J, Mobley WC, Holaday JW. Neurological dysfunction after intrathecal injection of dynorphin A (1-13) in the rat. II. Nonopioid mechanisms mediate loss of motor, sensory and autonomic function. J Pharmacol Exp Ther 1988; 246: 1167-1174.

64 Bakshi R, Ni R-X, Faden Al. N-methyl-D-aspartate (NMDA) and opioid receptors mediate dynorphin-induced spinal cord injury: behavioral and histological studies. Brain Res 1992; 580: 255-264.

65 Mao J, Price DD, Phillips LL, Lu J, Mayer DJ. Increases in protein kinase C gamma immunoreactivity in the spinal cord of rats associated with tolerance to the analgesic effects of morphine. Brain Res 1995; 677: 257-267. 